\title{
Isolation and antibiotic resistance pattern of vancomycin-resistant Enterococcus fascium strains in clinical samples in Tabriz hospitals.
}

\author{
Jafari-Sales $\mathbf{A}^{1^{*}}$, Tarbiat-Nazloo $D^{1}$, Shadi-Dizaji $A^{2}$ \\ ${ }^{1}$ Department of Microbiology, Kazeroon branch, Islamic Azad University, Kazeroon, Iran \\ ${ }^{2}$ Department of Biotechnology, Ataturk University, Ataturk, Turkey
}

\begin{abstract}
Background: In recent decades, Enterococci have been identified as an important pathogen. Resistance of these bacteria to antibiotics causes major problems in the therapeutic process. Therefore, the aim of this study was to determine the antibiotic resistance pattern of Enterococcus fascium strain in clinical samples.

Methods: In this research, 219 samples of Enterococci from clinical specimens including: Blood and urine were studied in Tabriz hospitals. All strains were identified by standard and bacteriological tests, and then antibiotic resistance patterns of bacteria isolated by Kirby-Bauer disc diffusion method were performed. Also, the minimum inhibitory concentration (MIC) was determined by E-Test method.

Results: Of 219 strains of Enterococcus, $86(39.26 \%)$ strains belong to the species of $E$. fascium. The highest resistance to antibiotics was tetracycline $(83.7 \%)$ and erythromycin $(65.1 \%)$, and lowest compared to linezolid $(0 \%)$ and teicoplanin $(18.6 \%)$. Based on the E-Test, $29(33.7 \%)$ sample was resistant to vancomycin.

Conclusion: Considering the increasing number of infectious diseases caused by resistant strains of Enterococcus genus and its dissemination in the hospital environment, it is very necessary to use infection control measures to eliminate the potential sources of infection and prevent it from developing.
\end{abstract}

Keywords: E. fascium, Vancomycin, Antibiotic resistance pattern.

Accepted on March 8, 2018

\section{Introduction}

Enterococci are optional anaerobic and gram-positive cocci that are considered as the natural flora of the intestines of warmblooded animals, including humans [1]. Of the more than 20 species of Enterococcus, the two most human pathogens of this bacterium are Enterococcus faecalis (85-90\%) and Enterococcus fascium (5-10\%) [2]. Enterococci are considered as a major cause of hospital infections and acquired infections from the community [3,4]. In the last two decades, Enterococci have been identified as one of the most important human pathogens. These organisms are inherently resistant to a large number of antibiotics and, moreover, they are also increasingly able to obtain new resistance [4]. Infections caused by antibiotic-resistant Enterococci are considered as a systemic therapeutic system.

These infections are important in many aspects, including mortality and pathogenicity in patients, increasing patient hospital admission life expectancy, increased costs for prolonged stay and diagnostic and therapeutic interventions. One of the sources of infection is the medical equipment and Medical device that the resources of these resources can be transmitted directly or indirectly to a new host [5-8]. Most Enterococci are resistant to $\beta$-lactam antibiotics and glycopeptide, Therefore their simultaneous use with an aminoglycoside is needed to treat the most serious Enterococcal infections, such as endocarditis and meningitis
[9]. Vancomycin is often the last resort to treat infections of gram-positive bacteria, especially Enterococci [10].

In recent years, researchers have found that despite public health improvements, there is still a significant increase in bacterial infections, especially Enterococcus, the main cause of which is the transfer of these resistors by conjugation, plasmids and transplants are of a genus or other Genus of bacteria [11]. Therefore, it is essential to perform drug sensitivity for proper treatment and prevention of resistant strains. For proper treatment and prevention of resistant strains, it seems necessary. The purpose of this study was to identify antibiotic resistance patterns of $E$. fascium strains.

\section{Materials and Methods}

In this descriptive cross-sectional study, 219 samples of Enterococci from different clinical specimens including urine, blood from hospitalized sector and outpatients of hospitals and treatment centres in Tabriz during a one-year period from May 2016 to May 2017 were collected by Simple Random Sampling. A questionnaire was prepared for all patients and the required information (age, sex, location of infection) was recorded according to ethical charter. Initially, the strains of Enterococci were identified using biochemical tests (Gram stain, catalase, Bacitracin sensitivity, grow in medium containing $6.5 \% \quad \mathrm{NaCl}, \quad$ L-pyroglutamic and acid- $\beta$ naphthylamide) $[7,8,12]$. 
Sensitivity test was performed by Kirby-Bauer disk diffusion method to obtain antibiotic resistance patterns of isolated from patients. Antibiotic disks used in this test includeing: Vancomycin, Erythromycin, Gentamicin, Linezolid, Ciprofloxacin, Teicoplanin, Tetracycline and co-trimoxazole was the Iranian Padtan-Teb medicine Company. For this purpose, the disks were sterilized with appropriate distance from each other on the Muller Hinton Agar medium and then incubated for $24 \mathrm{~h}$ at $37^{\circ} \mathrm{C}$. Then the diameter of the inhibition zone of bacterial growth was measured and compared with the standard table.

Finally, the results were expressed as sensitive, semi-sensitive, and resistant [13-15] based on the diameter of the growth halo around the discs. The minimum inhibitor concentration of MIC was determined through E-Test method (Himedia Indian Company) based on the Clinical Standards Institute (CLSI) and the findings were interpreted according to CLSI standards guideline [5]. The results were analyzed using SPSS software (version 19) and chi square test. In all cases, $\mathrm{p}<0.05$ was considered significant.

\section{Results}

Of the 219 samples of Enterococcus, 152 (69.4\%) samples were isolated from the urine and $67(30.6 \%)$ samples were isolated from the blood. $45(20.5 \%)$ of samples were collected from hospitalized sector and $174(79.5 \%)$ of them were collected from outpatients. The mean age of patients was 48.4 \pm 27 and variation range was between 10 months to 85 years old. $168(65.63 \%)$ belonged to men and $88(34.37 \%)$ belong to women. $86(39.26 \%)$ of the samples belonged to fascium species. There was no significant difference in the distribution of fascium species between age groups ( $\mathrm{p}>0.05) .52(60.5 \%)$ samples were isolated from the urine and 34 (39.5\%) samples were isolated from the blood. No statistically significant differences were found regarding frequency of fascium species in Sample type ( $p>0.05) .20$ (23.3\%) of samples were collected from hospitalized sector and $66(76.7 \%)$ of them were collected from outpatients.

There was no significant difference in the distribution of fascium species between hospitalized sector and outpatients $(\mathrm{P}>0.05) .53(61.63 \%)$ belonged to men and $33(38.37 \%)$ belong to women. There was no significant difference in the distribution of fascium species between male and female groups $(\mathrm{P}>0.05)$. Based on antibiotic susceptibility and resistance test, E. fascium has the highest resistance to antibiotics tetracycline $(83.7 \%)$ and erythromycin $(65.1 \%)$, and the lowest resistance linezolid $(0 \%)$ and ticoplanin $(18.6 \%)$ (Figure 1).

There was no statistically significant difference between the place of infection and resistance to antibiotics $(\mathrm{P}>0.05)$. Of the 86 samples of E. fascium using the E-test method 7 (31.4\%) strains were $256 \mu \mathrm{g} / \mathrm{ml}, 2(2.3 \%)$ strains were more than 32 $\mu \mathrm{g} / \mathrm{ml}, 73$ strains were between $4 \mu \mathrm{g} / \mathrm{ml}$ and $32 \mu \mathrm{g} / \mathrm{ml}$.

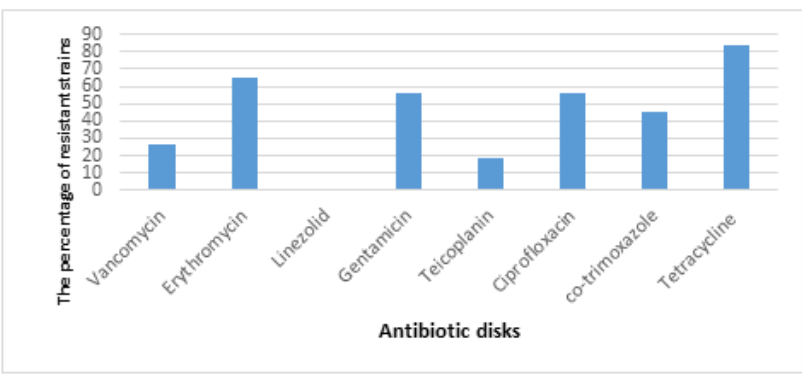

Figure 1. Antibiotic resistance rates of isolated E. fascium strains

\section{Discussion}

VRE is known as one of the most important causes of hospital infections in patients with a weakened immune system. In addition, the presence of resistant Enterococci in human societies acts as a source for hospital infections [16]. In this study, like several other studies, resistance to E. fascium is more than other Enterococci [17]. It has been proven that in most cases, due to the excessive use of antibiotics, we have seen many drug resistances in pathogens. This leads to failure in treatment and the emergence of many complications, despite the high cost of treatment [18]. Drug resistance to antibiotics in different regions of Iran and the world due to genetic variation, the difference in the consumption of antibiotics and difference in the availability of new extended spectrum are different. Until 1981-86, ciprofloxacin resistance to enterococci was not common, but in 1990, resistance significantly increased to $15.2 \%$. [19,20]. According to a study by Seifi in 2008 , high resistance (about 40\%) to ciprofloxacin was observed among clinical isolates and sewage, which can be used as the first treatment option for the treatment of various types of urinary tract infections [21]. The reasons for increasing the role of Enterococci in hospital infections can be attributed to the use of antibiotics that are resistant to them [5]. In 2006, Fatholazadeh and his colleagues reported that the prevalence of E.fascium was $30 \%$ in urinary tract infections in three hospitals in Tehran. Which is consistent with the findings of the present study [14]. In the present study, the prevalence of vancomycin resistant Enterococci was $33.7 \%$. The prevalence of vancomycin-resistant Enterococci was reported as 6.8\%, 10\%, and $7.7 \%$, respectively [22-24]. Also in domestic studies, the prevalence of vancomycin-resistant Enterococci was reported to be $4.7 \%, 5.6 \%, 12 \%$, and $23 \%$, respectively [25-28]. However, Salah et al. [29], Loza et al. [30], And Guiney [31] did not find any Enterococci resistant to vancomycin. The study of 414 Enterococci, 19(4.6\%) isolates of vancomycin resistant Enterococci were identified. By specifying the species, all 19 samples were resistant to vancomycin $E$. faecium [32]. The prevalence of erythromycin resistance in Enterococcal isolates in this study was $65.1 \%$, which was lower, higher and close to the results obtained in Tabriz (91.24\%), Lebanon (59\%), and India (85\%) [33-35]. In the current study, resistance to ciprofloxacin was $56 \%$, and the results were higher than those of similar studies in France (14.3\%), Japan (10\%), Lebanon (34\%), Pakistan (11.57\%), and Tabriz (60.58\%) [33,34,36,37]. In this study, the least resistance to Linezolid antibiotics was observed Which 
Citation: Jafari-Sales A, Tarbiat-Nazloo D, Shadi-Dizaji A. Isolation and antibiotic resistance pattern of vancomycin-resistant Enterococcus fascium strains in clinical samples in Tabriz hospitals. Microbiol Curr Res. 2018;2(2):36-40.

consistent with the study of Shafiyabi et al in 2013 [38]. But Loza et al. reported $100 \%$ sensitivity to linezolid and ampicillin antibiotics [31].

\section{Conclusion}

Based on the results of the present study, a significant percentage of Enterococcal strains show resistance to various antibiotics, Therefore, proper treatment requires strategies to control and prevent the release of resistant strains, as well as continuous monitoring for the detection of emerging resistance traits in these bacteria.

\section{References}

1. Murray BE. The life and times of the Enterococcus. Clin Microbiol Rev. 1990;3:46-65.

2. Saeed AK, Mohamad SN, Ashraf AK. Selective isolation of multi drug resistant Entrococcus spp, from poultry and dairy farms: detection of virulence and vancomycin resistance gene markers by PCR. Mol Cell Prob. 2005;19:27-34.

3. Flemmig TF, Milian E, Karch H, et al. Differential clinical treatment outcome after systemic Metronidazole and amoxicillin in patients harboring Actinobacillus Actinomycetemcomitans and/or Prophyromonas Gingivalis. J Clin Periodontol. 1998;25:380-7.

4. Tankovic J, Mahjoubi F, Courvalin P, et al. Development of fluoroquinolone resistance Enterococcus faecalis and role of mutations in the DNA Gyrase gyrA gene. Antimicrobial Agents Chemother. 1996;40:2558-61.

5. Modi GB, Soni ST, Patel KJ, et al. Prevalence of vancomycin resistant Enterococci in tertiarycare hospital, western, India. Int J Microbiol Res. 2012;4:182-5.

6. Struelens MJ. The epidemiology of antimicrobial resistance in hospital acquired infections: Problems and possiblesolutions. 1998;317:652-4.

7. Jafari-Sales A, Jafari B, Rasi-Bonab F, et al. Multi-Drug Resistance Patterns of Enterococcus faecalis Strains Isolated from Clinical Specimens of the Hospitals and Treatment Centers of Marand City. Iran J Micro Nano Biomed. 2017;2:31-6.

8. Jafari-Sales A, Sayyahi J, Akbari-Layeg F, et al. Identification of gyrA Gene in Ciprofloxacin-Resistant Enterococcus faecalis in Strains Isolated from Clinical Specimens in Hospitals and Clinics of Tabriz and Marand Cities. Arch Clin Microbiol. 2017;8:63.

9. Willems RJL, Bonten MJM. Glycopeptide-resistant Enterococci: deciphering virulence, resistance and epidemicity. Curr opinion ininfect dis. 2007;20:384-90.

10. Woodford N. Biological counterstrike: antibiotic resistance mechanisms of Gram-positive cocci. Clin Microbiol Infect. 2005;11:2-21.

11. Chow J, Thal L, Perri M, et al. Plasmid-associated hemolysin and aggregationsubstance production contribute to virulence in experimental Enterococcal endocarditis. Antimicrob Agents Chemother. 1993;37:2474-7.
12. Facklam RR, Collins MD. Identification of Enterococcus species isolated from human infections by a conventional test scheme. J Clin Microbiol. 1989;27:731-4.

13. Forbes BA, Sahm DF, Weissfeld A. Bailey\& Scott's Diagnostic Microbiology. Elsevier Health Sciences. 2002;236-40.

14. Fatholazadeh B, Hashemi BF, Emaneini M, et al. Detection of vancomycin resistant Enterococci (VRE) isolated from urinary tract (UTI) in Tehran, Iran. 2006;14:141-5.

15. Anbumani N, Menon $\mathrm{T}$, Kalyani J, et al. Isolation, distribution and prevalence of various species of Enterococci isolated from clinical specimens in a tertiary care hospital. Ind J of pathol microbiol. 2005;48:534-7.

16. Mendez-Alvarez S, Perez-Hernandez X, Claverie-Martın F. Glycopeptide resistance in Enterococci. Int Microbiol. 2000;3:71-80.

17. Huycke MM, Sham DF, Gilmore MS. Multidrug resistant Entrococci:The nature of problem and an agenda for the future. Emerge Infect Dis. 2002;4:239-49.

18. Kim JM, Song YG. Vancomycin-Resistant Enterococcal Infections in Korea.Yonsei Med J.1998;39:562-8.

19. Matar MJ, Tarrand J, Raad I, et al. Colonization and infection with vancomycinresistant Enterococcus among patients with cancer, Am J Infect Control. 2006;34:5346.

20. Manero A, Blanch AR. Identification of Enterococcus spp. with a biochemical key. Appl Environ Microbiol. 1999;65:4425-30.

21. Saifi M, Soltan MM, Pourshafie MR, et al. High-level resistance of $\mathrm{E}$. faecium and $\mathrm{E}$. faecalis isolates from municipal sewage treatment plants to gentamycin. Iranian J Pub Health. 2009;37:103-7.

22. Fernandes SC, Dhanashree B. Drug resistance and virulence determinants in clinical isolates of Enterococcus species. Ind J Med Res. 2013;137:981-5.

23. Harris AD, Nemoy L, Johnson JA, et al. Co-carriage rates of vancomycin-resistant Enterococcus and extendedspectrum beta-lactamase- producing bacteria amonga cohort of intensive care unit patients: implications for anactive surveillance program. Inf Control \& Hospital Epidem. 2004;25:105-8.

24. Zhanel GG. Canadian Antimicrobial Resistance Alliance (CARA), Hoban DJ Antimicrobial-resistant pathogens in intensive care units in Canada: results of the Canadian National Intensive Care Unit (CAN-ICU) study, 2005-2006. Antimicrob Agents Chemother. 2008;52:1430-7.

25. Ghasemi A, Moniri R, Musavi GA. The survey of multi drug resistant of Enterococcus faecium isolated from clinical samples in shahid Beheshti and Shabeeh khani hospitals. Iranian J Med Microb. 2009;3:21-6.

26. Eshraghi S, Talebi M, Pourshafie M, et al. The prevalence and molecular characterization of vancomycin resistant gram positive cocci isolated from patients in Tehran. Iran J Med Microbiol. 2007;1:9-15.

27. Teymournejad O, Mohabati Mobarez A, Hosseini Doust R. Epidemiologic evaluation of vancomycin resistant genes 
in Enterococcus spp. isolated from clinical samples. J Fasa Univ Med Sci. 2011;2:1-6.

28. Emaneini M, Aligholi M, Aminshahi M. Characterization of glycopeptides aminoglycosides and macrolide resistance among Enterococcus faecalis and Enterococcus faecium isolates from hospitals in Tehran. Pol J Microbiol. 2008;57:173-8.

29. Salah R, Dar-Odeh N, Hammad OA, et al. Prevalence of putative virulence factors and antimicrobial susceptibility of Enterococcus faecalis isolates from patients with dental Diseases. BMC Oral Health. 2008;8:17.

30. Guiney M, Urwin, G. Frequency and antimicrobial susceptibility of clinical isolates of Enterococci. Eur J Clin Microbiol Infect Dis. 1993;12:362-6.

31. Loza E. Comparative in vitro activity of daptomycin against gram-positive microorganisms: SENTRY surveillance program, Spain (2002-2006) Enferm Infecc Microbiol Clin. 2008;26:489-94.

32. Sedaghat M, Rahimi F, Pourshafie MR, et al. Studies of vancomycin resistant Enterococcus faecium isolated from clinical samples in Tehran, Iran. Curr Res Bacteriol. 2012;5:53-8.

33. Akhi MT, Farzaneh F, Oskouei M. Study of Enterococcal susceptibility patterns isolated from clinical specimens in Tabriz, Iran. Pak J MedSci. 2009;25:211-6.

34. Zouain MG, Araj GF. Antimicrobial resistanc of Enterococci in Lebanon. Int $\mathrm{J}$ Antimicrob Agents. 2001;17:209-13.
35. Mathur P, Kapil A, Chandra R, et al. Antimicrobial resistance in Enterococcus faecalis at atertiary care centre of northern India. Indian J Med Res. 2003;118:25-8.

36. Miskeen PA, Deodhar L. Antimicrobial susceptibility pattern of Enterococcus species from urinary tract infections. J Assoc Physicians India. 2002;50:378-81.

37. Nakanishi N, Yoshida S, Wakebe H, et al. Mechanisms of clinical resistance to fluoroquinolones in Enterococcus faecalis. Antimicrob Agents Chemother. 1991;35:1053-9.

38. Shafiyabi S, Mariraj J, Sumathi S, et al. Emergence of vancomycin resistant Enterococci in a tertiary care hospital in South India. Int J Pharm Biomed Res. 2013; 4:111-3.

\section{Correspondence to:}

Abolfazl Jafari-Sales

Department of Microbiology,

Kazeroon branch, Islamic Azad University,

Kazeroon, Iran.

Tel: +98(0)914-7611841

E-mail: a.jafari_1392@yahoo.com 